\title{
Diferenciação morfológica e anatômica em populações de "ipecacuanha" - Psychotria ipecacuanha(Brot.) Stokes (Rubiaceae) ${ }^{1}$
}

\author{
MARTA CAMARGO DE ASSIS² e ANA MARIA GIULIETTI ${ }^{3}$
}

(recebido em 30/07/98; aceito em 21/02/99)

\begin{abstract}
Morphological and anatomical differentiation in populations of "ipecacuanha" - Psychotria ipecacuanha (Brot.) Stokes (Rubiaceae)). Psychotria ipecacuanha is a medicinal plant of the Rubiaceae family. The roots are very important for the production of emetine. The species presents a disjunction in its geographical distribution. It occurs in Central America (from Nicaragua to Northwestern America do Sul) and in Brazil: in the Southern Amazonian Forest (Rondônia and Mato Grosso) and in the Atlantic Forest (Pernambuco to Paraná). Morphological data of populations from the three areas were used to establish the circunscription of the species and the possible infra-specific taxa. It was concluded, through the analysis of major components, that there are no significant differences among the individuals of the populations. The few individual differences observed are not related to the geographic distribution of the populations, so the "ipecacuanha" was considerated single species Psychotria ipecacuanha (Brot.) Stokes. In addition to the taxonomical analysis, some anatomical and chromosomal data are presented here.
\end{abstract}

RESUMO - (Diferenciação morfológica e anatômica em populações de "ipecacuanha" Psychotria ipecacuanha (Brot.) Stokes (Rubiaceae)). Psychotria ipecacuanha é uma espécie medicinal da família Rubiaceae, importante pela produção em suas raízes do alcalóide emetina. Foram feitas análises das três populações disjuntas que compõem a espécie e que ocorrem na América Central (Nicarágua, Costa Rica e Panamá) e Colômbia, sul da Floresta Amazônica (Rondônia e Mato Grosso) e Mata Atlântica (Pernambuco até Paraná). Foram utilizados, no estabelecimento dos limites inter e intraespecíficos, todos os dados morfológicos vegetativos e reprodutivos disponíveis e feita análise dos componentes principais, que permitiram concluir que não existem diferenças significativas entre as populações examinadas. As poucas diferenças individuais observadas não estão relacionadas com a distribuição geográfica das populações examinadas. Como conclusão, a ipecacuanha ao longo de toda sua distribuição geográfica foi considerada como uma só espécie, Psychotria ipecacuanha (Brot.) Stokes. Além da análise taxonômica, são apresentados neste trabalho dados anatômicos e sobre o número de cromossomos da espécie.

Key words - Psychotria ipecacuanha, taxonomy, Rubiaceae

\section{Introdução}

A ipecacuanha ou ipeca, poaia e poalha, como também é conhecida, é uma planta medicinal do subosque de florestas, com distribuição disjunta no Brasil, Colômbia e América Central.

Segundo Figueiredo (1935) ocorrem dois "tipos" de ipecacuanha: a ipecacuanha anelada menor, ou ipecacuanha do Brasil, e a ipecacuanha anelada maior, ou ipecacuanha de Cartagena ou de Nova Granada. Tal nomenclatura está associada ao maior ou menor tamanho de protuberâncias semelhantes a anéis que envolvem as raízes, provavelmente devido à contração destas.

Gattoni (1960) mencionou que a ipecacuanha de Cartagena é pertencente à espécie Cephaelis acuminata Karsten, e que a mesma é nativa da Co-

1. Dissertação de mestrado de M.C. Assis, bolsista CAPES.

2. EMBRAPA/CENARGEN, SAIN Parque Rural, Caixa Postal 02372, 70849-970 Brasília, DF, Brasil.

3. Departamento de Ciências Biológicas, Universidade Estadual de Feira de Santana, BR 116, Km 03, 44031-460 Feira de Santana, BA, Brasil. lômbia, Venezuela, Panamá e Nicarágua. Porém, Torres (1972) refere a ipecacuanha da Colômbia com o nome de Cephaelis ipecacuanha (Brot.) A. Rich. A ipecacuanha do Brasil foi denominada inicialmente por Brotero (1802) como Callicocca ipecacuanha. Posteriormente foi denominada com diferentes epítetos como Psychotria ipecacuanha (Brot.) Stokes, Ipecacuanha officinalis Arruda ex Koster, Cephaelis ipecacuanha (Brot.) A. Rich. Psychotria emetica Vell. e Uragoga ipecacuanha Baill. Vários autores como Gattoni (1960) e Akerele et al. (1991) aceitam Cephaelis ipecacuanha (Brot.) A. Rich. como o nome válido para o táxon.

O uso farmacológico da ipecacuanha está ligado à presença de dois alcalóides em suas raízes: a emetina e a cefelina que conferem à planta um poder emético e amebicida.

Tanto a ipecacuanha do Brasil como a de Cartagena têm morfologia das raízes e usos similares, associado à presença dos mesmos alcalóides. Addor (1945), no entanto, mostrou que a porcentagem de alcalóides varia de acordo com a procedência da raiz, ocorrendo maior teor nas plantas do Brasil, seguido 
pelas plantas da Colômbia e da América Central. As plantas de ipecacuanha cultivadas na Índia possuem o menor teor de alcalóides totais.

A maioria dos trabalhos sobre a ipecacuanha são relacionados aos estudos farmacológicos, o que deixa lacunas, principalmente no que se refere à taxonomia, morfologia e conservação. Este trabalho visa responder às seguintes questões: a planta ipecacuanha seria só uma espécie ao longo de sua distribuição geográfica? Ocorreriam táxons infra-específicos? Também pretende mostrar as variações morfológicas que ocorrem nas várias populações disjuntas da ipecacuanha nas Américas do Sul e Central e fornecer novos dados sobre anatomia e o número de cromossomos, visando contribuir para a conservação da espécie.

\section{Material e métodos}

Visando resolver o problema taxonômico de Psychotria ipecacuanha, foi feito um estudo morfológico comparado das populações de ipecacuanha, sendo analisadas 97 populações ao longo da distribuição geográfica, incluindo as seguintes características mensuráveis: comprimento da parte aérea da planta; diâmetros das raízes e dos ramos; comprimento dos entrenós, pecíolos e estípulas; comprimento e largura das folhas e presença e comprimento dos acúmens das folhas. As medidas foram feitas com auxílio de uma régua. Foi também analisada a pilosidade dos ramos e dos pedúnculos. Estas análises foram baseadas no exame de exsicatas provenientes de diversos herbários nacionais e estrangeiros. A relação desses herbários é citada a seguir e as siglas usadas estão de acordo com o Index Herbariorum (Stafleu 1981): BHCB, CEN, F, MO, NY, R, RFA, SP. Grande parte do material estudado foi decorrente do extenso programa de coletas realizadas entre 1989-1991, como parte do Projeto "Coleta e Conservação de Germoplasma de Ipecacuanha" desenvolvido pelo CENARGEN, dentro do Programa Cultivos Pioneiros (FINEP/CNPq) e que cobriu todos os possíveis locais de ocorrência natural da espécie no Brasil. Todo o material coletado foi depositado no herbário CEN. Para uma melhor comparação das populações estudadas foi feita a análise dos componentes principais (Morrison 1976). A lista completa do material examinado, destacando os utilizados nas diversas análises, encontra-se no final do item material e métodos.

Para os estudos anatômicos utilizaram-se segmentos da porção mediana de folhas, das raízes e dos caules de plantas coletadas no ambiente natural e cultivadas a partir de estacas de raiz em casa de vegetação. Os materiais foram preservados em álcool 70\%, desidratados em série etanólica e emblocados em parafina (Johansen 1940). As amostras de folhas foram seccionadas transversalmente com o auxílio do micrótomo rotativo, em secções com espessura de $12 \mu \mathrm{m}$ e as de raiz e caule seccionadas com micrótomo de deslize. As secções do limbo das folhas foram coradas com safranina e "fast-green" (Sass 1951), e as de caules e raízes com fucsina e azul de astra (Roeser 1962). Os coléteres foram seccionados longitudinalmente seguindo-se o método apresentado por Lersten (1974). Foram estudadas coleções provenientes dos Estados de Minas Gerais (Skorupa 751 \& Assis), Espírito Santo (Skorupa 759 \& Assis),
Mato Grosso (Skorupa et al. 714) e Rondônia (Skorupa 612 \& Assis).

A contagem do número cromossômico foi feita através da utilização de flores previamente fixadas em Carnoy. Sob microscópio estereoscópico as anteras foram retiradas, esmagadas e coradas em carmim propiônico. As lâminas com células meióticas de grão de pólen foram examinadas e as que se encontravam em fase apropriada para contagem foram fotografadas em fotomicroscópio Zeiss. A contagem do número cromossômico foi feita diretamente a partir das lâminas e baseada em Skorupa 753 \& Assis.

Para a análise de viabilidade do pólen, foram examinadas seis coleções: Skorupa 751 \& Assis, Skorupa 753 \& Assis, Skorupa 759 \& Assis, Skorupa et al. 714 e Skorupa 612 \& Assis. Foram escolhidas flores previamente fixadas em Carnoy com os grãos de pólen desenvolvidos e prontos para serem liberados. As anteras foram retiradas sob microscópico estereoscópico, esmagadas e coradas com carmim propiônico. Foram examinados 400 grãos de pólen, sendo que os que se encontravam bem corados e morfologicamente normais foram considerados viáveis, enquanto os não ou pouco corados e morfologicamente mal-formados foram considerados inviáveis.

Material examinado, destacando-se entre colchetes os números seqüenciais da legenda da figura $64 \mathrm{e}$, das tabelas 1-3 usados na análise dos componentes principais: BRASIL: BAHIA: Potiraguá, 25/6/1991, L.A. Skorupa 941 \& M.C. Assis (CEN); Ibicaraí, 20/5/1920, s. col. (SP 4314) [38]; idem, 9/11/1989, L.A. Skorupa \& M.C. Assis 767 [39], idem, 9/11/1989, L.A. Skorupa \& M.C. Assis 768 (CEN); Itapé, 25/6/1991, L.A. Skorupa \& M.C. Assis 930 (CEN). ESPÍRITO SANTO, picada da Lagoa do Braz, 15/4/1934, J.G. Kuhlmann 225 (R) [40]; Colatina, 24/2/1944, F. C. Hoehne 52488 (SP) [43]; Lajinha, 5/11/1989, L.A. Skorupa \& M.C. Assis 759 (CEN) [44]; Linhares, 3/11/1989, L.A. Skorupa \& M.C. Assis 757 (CEN); idem, 6/11/1989, L.A. Skorupa \& M.C. Assis 760 (CEN); idem, 6/11/1989, L.A. Skorupa \& M.C. Assis 761 (CEN); idem, 6/11/1989, L.A. Skorupa \& M. C. Assis 762 (CEN). MATO GROSSO: matas do Rio Jauru, 12/1908, F.C. Hoehne 927 (R) [14]; idem, 12/1908, F.C. Hoehne 894 (SP) [15]; matas dos Rios Manoel Correia e São Miguel, 4/1919, F.C. Hoehne 2485 (R) [13]; extremo nordeste de Mato Grosso, 4/1919, F.C. Hoehne 2485R (R) [11]; matas entre os Rios São Domingos e São Miguel, 3/1919, F.C. Hoehne 2422R (R) [12]; cabeceira do Rio Mingão, 5/1919, F.C. Hoehne 2358-K (R) [16]; Humaitá, 13/3/1894, L.A.M. Lindman 3081 (R) [17], (F); Tapirapoã, 1/9/1914, F.C. Hoehne 5627 (R) [18]; idem, 1/9/1914, F.C. Hoehne 5628 (R) [19]; Barra do Bugres, 16/7/1944, s. col. (SP 52718) [20]; idem, 15/7/1988, L.A. Skorupa et al. 571 (CEN); idem, 15/7/1988, L.A. Skorupa et al. 572 [26] (CEN); idem, 15/7/1988, L.A. Skorupa et al. 573 (CEN); idem, 15/7/1988, L.A. Skorupa et al. 574 (CEN); idem, 15/7/1988, L.A. Skorupa et al. 575 (CEN); idem, 16/7/1988, L.A. Skorupa et al. 576 (CEN); idem, 16/7/1988, L.A. Skorupa et al. 577 (CEN); idem, 17/7/1988, L.A. Skorupa et al. 580 (CEN) [21]; idem, 25/5/1989, L.A. Skorupa et al. 689 (CEN) [22]; idem, 25/5/1989, L.A. Skorupa et al. 690 (CEN) [25]; idem, 25/5/1989, L.A. Skorupa et al. 693 (CEN) [24]; idem, 25/5/1989, L.A. Skorupa et al. 694 (CEN) [23]; idem, 25/5/1989, L.A. Skorupa et al. 695 (CEN); idem, 25/5/1989, L.A. Skorupa et al. 696 (CEN); Salto do Céu, 19/7/1988, L.A. Skorupa et al. 589 (CEN); idem, 19/7/1988, L.A. Skorupa et al. 590 (CEN); idem, 5/1989, L.A. Skorupa et al. 707 (CEN) [28]; idem, 5/1989, L.A. Skorupa et al. 708 (CEN) [27]; Cárceres, 1954, J.M. Langly 3 (F); idem, 21/7/1988, L.A. Skorupa et al. 594 (CEN) [29]; Mirassol D’Oeste, 22/7/1988, L.A. Skorupa et al. 595 (CEN); Novo Horizonte, 24/7/1988, L.A. Skorupa et al. 596 (CEN) [30]; Pontes e Lacerda, 26/7/1988, L.A. Skorupa et al. 602 (CEN) [31]; Pontes e Lacerda, 26/7/1988, L.A. Skorupa et al. 607 (CEN) [32]; Vila Bela da 
Santíssima Trindade, 26/5/1989, L.A. Skorupa et al. 700 (CEN) [36]; idem, 26/5/1989, L.A. Skorupa et al. 701 (CEN); idem, 26/5/1989, L.A. Skorupa et al. 702 (CEN) [35]; Rio Branco, 6/1989, L.A. Skorupa et al. 712 (CEN) [34]; idem, 6/1989, L.A. Skorupa et al. 714 (CEN); idem, 6/1989, L.A. Skorupa et al. 719 (CEN) [33]; s. loc., 8/1821, L. Riedel s.n. (F 617738); s. loc. 8/1845, M Weddell 3394 (NY, F); s. loc. 8/1845, M. Weddell 3351 (F); s. loc. 1848, M. Weddell 3384 (NY). MINAS GERAIS: Tombos, Fazenda das Antilhas, 15/7/1935, Mello-Barreto 1631 (R, NY) [48]; idem, 21/1/1936, Mello-Barreto 2002 (R) [45]; s.d., s.col (RFA 6787) [47]; idem, 1956, s.col. (RFA) [46]; Caratinga, Estação Biológica, 21/2/1984, P.M. Andrade \& M. A. Lopes 139 (BHCB); idem, 2/11/1989, L.A. Skorupa \& M. C. Assis 753 (CEN) [49]; 3/11/1989, L.A. Skorupa \& M. C. Assis 757B (CEN); Carangola, 1/11/1989, L.A. Skorupa \& M. C. Assis 751 (CEN) idem, 1/11/1989, L.A. Skorupa \& M. C. Assis 752 (CEN); Ipanema, 21/6/1991, L.A. Skorupa \& M. C. Assis 907 (CEN) Rio Casca, 1958, s.col. (BHCB 1574) [51]. PARANÁ: Alexandra, 6/3/1911, P. Dúsen 11488 (F). PERNAMBUCO: Olinda, 12/3 1925, B. Pickell 877 (SP) [37]. RIO DE JANEIRO: Porciúncula, 30/10/1989, L.A. Skorupa \& M. C. Assis 745 (CEN); idem, 31/ 10/1989, L. A. Skorupa \& M. C. Assis 746 (CEN) [52]; idem, 19/ 6/1991, L. A. Skorupa \& M. C. Assis 901 (CEN); Rio Bonito, 12/ 1969, s.col. (RFA 9244) [54]; Jacarepaguá, 13/3/1868, Glaziou 2609 (R) [53]. RONDÔNIA: Costa Marques, 31/7/1988, L.A Skorupa et al. 610 (CEN) [2]; 1/8/1988, L.A. Skorupa et al. 612 (CEN) [1]; idem, 28/5/1990, L.A. Skorupa \& M.C. Assis 826 (CEN); idem, 28/5/1990, L.A. Skorupa \& M.C. Assis 827 (CEN) idem, 28/5/1990, L.A. Skorupa \& M.C. Assis 828 (CEN); idem, 28/5/1990, L.A. Skorupa \& M.C. Assis 829 (CEN); idem, 28/5 1990, L.A. Skorupa \& M.C. Assis 833 (CEN); idem, 28/5/1990, L.A. Skorupa \& M.C. Assis 834 (CEN); idem, 28/5/1990, L.A Skorupa \& M.C. Assis 836; idem, 28/5/1990, L.A. Skorupa \& M.C. Assis 837 (CEN) [4]; idem, 28/5/1990, L.A. Skorupa \& M.C. Assis 838 (CEN); idem, 28/5/1990, L.A. Skorupa \& M.C. Assis 839 (CEN); idem, 28/5/1990, L.A. Skorupa \& M.C. Assis 840 (CEN) [3]; idem, 28/5/1990, L.A. Skorupa \& M. C. Assis 842 (CEN); Rolim de Moura, 24/5/1990, L.A. Skorupa \& M.C. Assis 775 (CEN) [10]; idem, 24/5/1990, L.A. Skorupa \& M.C. Assis 776 (CEN); idem, 24/5/1990, L.A. Skorupa \& M.C. Assis 777 (CEN) [5]; idem, 24/5/1990, L.A. Skorupa \& M.C. Assis 778 (CEN); idem, 24/5/1990, L.A. Skorupa \& M.C. Assis 779 (CEN) idem, 24/5/1990, L.A. Skorupa \& M.C. Assis 780 (CEN); idem, 24/5/1990, L.A. Skorupa \& M.C. Assis 781 (CEN); idem, 25/5/1990, L.A. Skorupa \& M.C. Assis 800 (CEN); idem, 25/5/1990, L.A. Skorupa \& M.C. Assis 801 (CEN); idem, 25/5/1990, L.A. Skorupa \& M.C. Assis 802 (CEN); idem, 25/5/1990, L.A. Skorupa \& M.C. Assis 803 (CEN); idem, 25/5/1990, L.A. Skorupa \& M.C. Assis 804 (CEN); idem, 25/5/1990, L.A. Skorupa \& M.C. Assis 805 (CEN); idem, 25/5/1990, L.A. Skorupa \& M.C. Assis 806 (CEN); idem, 26/5 1990, L.A. Skorupa \& M.C. Assis 807 (CEN); idem, 26/5/1990, L.A. Skorupa \& M.C. Assis 808 (CEN); idem, 26/5/1990, L.A. Skorupa \& M.C. Assis 809 (CEN); idem, 26/5/1990, L.A. Skorupa \& M.C. Assis 810 (CEN); idem, 26/5/1990, L.A. Skorupa \& M.C. Assis 811 (CEN); idem, 26/5/1990, L.A. Skorupa \& M.C. Assis 812 (CEN) [9]; idem, 26/5/1990, L.A. Skorupa \& M.C. Assis 813 (CEN); idem, 26/5/1990, L.A. Skorupa \& M.C. Assis 814 (CEN); idem, 26/5/1990, L.A. Skorupa \& M.C. Assis 815 (CEN) [6]; idem, 26/5/1990, L.A. Skorupa \& M.C. Assis 820 (CEN); Cacoal, 26/5/1990, L.A. Skorupa \& M.C. Assis 816 (CEN) [8]; idem, 26/5/1990, L.A. Skorupa \& M.C. Assis 819 (CEN) [7]; Cerejeiras, 6/6/1990, L.A. Skorupa \& M. C. Assis 845 (CEN). SÃO PAULO, Serra da Mantiqueira, Fazenda do Cruzeiro, 12/1/1884, J. Saldanha 8484 (R); Ilha Seca, 1940, N. Santos s.n. (R). COLÔMBIA:
DARIEN: 1919, M.T. Dawe 862 (NY) [65]; BOLÍVAR: 14/2/1918, s.col. (NY); 4/3/1918, F.W. Pennell 4570 (NY) [66]; F.W. Pennell s.n. (NY) [67]; 04/7/1948, R.R. Castaneda 1145 (NY); 22/8/1966, J. Bruijin 1091 (NY); s.loc. 1961, D.V. Clay s.n. (F 1532220) [68] COSTA RICA: HEREDIA: 12/2/1985, H. Rodriguez 2 (F) [62] 4/6/1985, B. Hammel \& M. Grayum 14126 (MO); Los Chiles, 20/4/1938, J.M. Orozco 29 (F) [63]; s.d., J.V. Rodriguez s.n.(F) [64]. Nicarágua: Rio San Juan, 18/2/1983, A. Grijalva 2344 (MO); idem, 21/2/1984, P. Moreno 23181 (MO) [58]; idem, 10/7/1985, P. Moreno 26094 (MO) [57]; Zelaya, 29/11/1951, P. Shank \& A. Molina 4798 (F); idem, 20/12/1951, P. Shank \& A. Molina 4678 (F) [59]; idem, 11/8/1982, M. Araquistain 3025 (MO) [60]; idem, 3/10/1982, A. Laguna 80 (MO) [61]; s.loc. 1961, D. Clay s.n. (F 1531935). PANAMÁ: SAN BLAS: 17/8/1967, T.S. Elias 1770 (MO) [69]; DARIEN: 5/6/1959, s.col. (MO 1758758) [70]; idem, 25/6/1961, O.J. Sexton 146 A (MO) [72]; idem, 25/6/1961, O.J. Sexton 146 B (MO) [71]; idem, 21/6/1962, J.A. Duke 5027 (MO); idem, 18/7/1962, J.A. Duke 5237 A (MO) [73]; idem, 20/7/1962, J.A. Duke 5237 B (MO) [74]; idem, 21/8/1966, J.A. Duke 8566 (MO) [75]; idem, 22/3/1976, s.col. (MO 2381649) [76]; idem, 12/1978, K. Chin. s.n. (MO 2704720) [77]; ZONA DO CANAL: 7/7/1931, D.E. Starry 55 (MO) [92]; idem, 7/1931, s.col. (MO 1953862); idem, 1931, S. Aviles s.n. (F 642386) [93]; idem, s.d., L.H. Bailey \& E.Z. Bailey 23 (F) [87]; idem, 10/8/1940, s.col. (MO 1990181); idem, 7/1965, s.col. (MO 1827824) [89]; idem, S.M. Hayden 127 (MO) [91]; idem, 7/1965, S.M. Hayden 155 (MO) [90]; idem, 28/8/1967, S.M. Hayden 1037 (MO); idem, 6/ 12/1967, T.B. Croat 4096 (MO) [85]; idem, 6/12/1967, T.B. Croat 4104 (MO) [80] (F); idem, 12/12/1967, T.B. Croat 4269 (MO) [84]; idem, 2/10/1968, T.B. Croat 6609 (MO) [81]; idem, 28/9/ 1970, T.B. Croat 12427 (MO) [94]; idem, 12/6/1971, T.B. Croat 4975 (MO) [86]; idem, 25/6/1971, T.B. Croat 15117 (MO) [83]; idem, 3/2/1973, P. Busey \& T.B. Croat 237 (MO) [98]; idem, 26/ 7/1978, s.col. (MO 2704731) [79]; idem, 26/7/1978, s.col. (MO 2704735) [96]; idem, 27/7/1978, s.col. (MO 2704732 [96]; idem, 27/7/1978, s.col. (MO 2704733) [78]; idem, 27/7/1978, s.col. (MO 2704734) [97]; idem, 7/1982, R.J. Schamalzel 767 (MO) [88].

\section{Resultados e Discussão}

Os dados obtidos encontram-se apresentados pelo conjunto das populações ocorrentes no sul da floresta Amazônica: Rondônia e Mato Grosso; (tabela 1); na Mata Atlântica (tabela 2) e nas florestas da Colômbia e América Central (tabela 3). Observa-se grande variação no comprimento da parte aérea da planta, incluindo desde plantas acaules até com 50-60 $\mathrm{cm}$ de altura. Outras características como o diâmetro das raízes, dos ramos e dos entrenós são também associados a maior ou menor robustez das plantas.

As variações observadas, associadas ao comprimento e largura das folhas, estão expressas na variação das folhas, mostradas nas figuras 2-37. Essas variam desde elípticas até ovais, oblongo-lanceoladas ou obovais. As análises na variação das formas das folhas foram associadas com variações nas formas das estípulas e tipo de indumento, procurando-se uma associação com a distribuição geográfica das plan- 
tas (figuras 1-37). Observa-se que não há correlação entre os padrões de morfologia foliar encontrados e a distribuição geográfica. Quanto às estípulas e indumento também não foram observadas diferenças significativas. Quanto à presença ou não do acúmen das folhas e seu tamanho, verifica-se que as populações do Brasil (tabelas 1,2) apresentam normalmente folhas sem acúmen ou com acúmen pequeno, medindo entre $0,1-0,3 \mathrm{~cm}$, nas plantas da Mata Atlântica e $0,1-0,5 \mathrm{~cm}$, nas plantas da floresta Amazônica. Nas plantas da Colômbia e América Central (tabela 3 ), a variação ocorre de $0,2-1,1 \mathrm{~cm}$. Apenas os espé- cimes F911997 e Croat 4104 não apresentam acúmen. Outro caráter que se mantém mais ou menos constante é a presença de ramos e pedúnculos pubescentes em todas as plantas examinadas do Brasil e ramos e pedúnculos glabros nas plantas de fora do Brasil, embora o espécime Clay s. n. da Nicarágua apresente ramos pubescentes.

O nome correto da espécie merece uma consideração especial. Como foi visto na Introdução a espécie já recebeu vários nomes, associados principalmente a diferentes gêneros. O nome Cephaelis ipecacuanha (Brot.) A. Rich. tem sido o mais utilizado. Recente-

Tabela 1. Comparação dos caracteres morfológicos apresentados pelos exemplares de Psychotria ipecacuanha que ocorrem na floresta Amazônica, nos Estados de Rondônia e Mato Grosso. No.: número correspondente na figura 64; C.P.A.: comprimento da parte aérea da planta; Diâm/raiz: diâmetro da raiz; Diâm/ramo: diâmetro do ramo; Compr. int.: comprimento do internó; Compr. peci.: comprimento do pecíolo; Compr. estip.: comprimento da estípula; Compr. folha: comprimento da folha; Larg. folha: largura da folha; Compr. acum.: comprimento do acúmen; Ramo pube.: pubescência do ramo; Pedu. pube.: pubescência do pedúnculo. + (presente), $-($ ausente).

\begin{tabular}{|c|c|c|c|c|c|c|c|c|c|c|c|c|}
\hline Coleção & $\mathrm{N}^{\mathrm{o}}$ & $\begin{array}{c}\text { C.P.A. } \\
(\mathrm{cm})\end{array}$ & $\begin{array}{l}\text { Diâm/ } \\
\text { raiz } \\
(\mathrm{cm})\end{array}$ & $\begin{array}{c}\text { Diâm/ } \\
\text { ramo } \\
(\mathrm{cm})\end{array}$ & $\begin{array}{c}\text { Compr. } \\
\text { int. } \\
(\mathrm{cm})\end{array}$ & $\begin{array}{c}\text { Compr. } \\
\text { peci. } \\
(\mathrm{cm})\end{array}$ & $\begin{array}{c}\text { Compr. } \\
\text { estip. } \\
(\mathrm{cm})\end{array}$ & $\begin{array}{c}\text { Compr. } \\
\text { folha } \\
(\mathrm{cm})\end{array}$ & $\begin{array}{l}\text { Larg. } \\
\text { folha } \\
(\mathrm{cm})\end{array}$ & $\begin{array}{l}\text { Compr. } \\
\text { acum. } \\
(\mathrm{cm})\end{array}$ & $\begin{array}{l}\text { Ramo } \\
\text { pube. }\end{array}$ & $\begin{array}{l}\text { Pedu. } \\
\text { pube. }\end{array}$ \\
\hline L.A.S.612 & 1 & 23,00 & 0,60 & 1,00 & 1,50 & 0,30 & 0,40 & 8,75 & 3.50 & 0,00 & + & + \\
\hline L.A.S.610 & 2 & 60,00 & 1,00 & 1,00 & 2,50 & 0,35 & 0,50 & 8,25 & 3,85 & 0,20 & + & + \\
\hline L.A.S.840 & 3 & 34,00 & 0,00 & 0,90 & 4,25 & 0,55 & 0,60 & 7,75 & 3,10 & 0,10 & + & + \\
\hline L.A.S.837 & 4 & 38,50 & 1,00 & 1,00 & 1,85 & 0,50 & 0,70 & 11,25 & 3,85 & 0,40 & + & + \\
\hline L.A.S. 777 & 5 & 33,00 & 0,70 & 1,00 & 3,25 & 0,75 & 1,00 & 6,85 & 3,75 & 0,10 & + & + \\
\hline L.A.S. 815 & 6 & 23,00 & 1,40 & 1,20 & 0,60 & 0,30 & 1,20 & 10,00 & 10,0 & 0,20 & + & + \\
\hline L.A.S.819 & 7 & 22,00 & 0,80 & 0,70 & 1,15 & 0,20 & 0,70 & 10,25 & 2,40 & 0,10 & + & + \\
\hline L.A.S. 816 & 8 & 54,00 & 0,70 & 1,00 & 5,00 & 0,50 & 0,70 & 9,25 & 4,45 & 0,00 & + & + \\
\hline L.A.S. 812 & 9 & 21,00 & 1,50 & 1,70 & 1,95 & 0,20 & 1,20 & 9,00 & 4,50 & 0,10 & + & + \\
\hline L.A.S.775 & 10 & 30,00 & 1,00 & 1,00 & 1,15 & 0,20 & 0,80 & 7,25 & 3,25 & 0,20 & + & + \\
\hline Hoeh.2485R & 11 & 60,00 & 0,00 & 1,50 & 0,45 & 0,75 & 0,50 & 6,75 & 3,10 & 0,00 & + & + \\
\hline Hoeh.2422R & 12 & 46,00 & 1,00 & 1,00 & 1,90 & 0,55 & 0,80 & 7,25 & 3,00 & 0,00 & + & + \\
\hline Hoeh.2485 & 13 & 50,00 & 0,70 & 1,20 & 1,15 & 0,00 & 0,40 & 7,25 & 2,75 & 0,10 & + & + \\
\hline Hoeh.927 & 14 & 30,00 & 0,00 & 1,30 & 0,00 & 0,00 & 0,00 & 10,25 & 6,70 & 0,00 & + & + \\
\hline Hoeh.894 & 15 & 36,50 & 1,20 & 1,00 & 2,15 & 0,60 & 0,50 & 10,00 & 4,25 & 0,00 & + & + \\
\hline Hoeh.2358K & 16 & 40,00 & 1,50 & 1,00 & 1,60 & 0,70 & 0,50 & 8,50 & 3,25 & 0,00 & + & + \\
\hline Lind.3081 & 17 & 20,00 & 1,20 & 1,20 & 1,35 & 0,30 & 0,70 & 5,95 & 3,35 & 0,30 & + & + \\
\hline Hoeh.5627 & 18 & 30,00 & 1,00 & 0,70 & 1,70 & 0,20 & 0,60 & 5,55 & 5,20 & 0,40 & + & + \\
\hline Hoeh.5628 & 19 & 30,00 & 1,00 & 0,80 & 0,85 & 0,20 & 0,70 & 5,75 & 3,35 & 0,50 & + & + \\
\hline SP52718 & 20 & 19,00 & 0,90 & 1,00 & 2,25 & 0,25 & 0,60 & 8,25 & 4,10 & 0,00 & + & + \\
\hline L.A.S.580 & 21 & 27,00 & 0,60 & 0,80 & 3,00 & 0,20 & 0,50 & 6,50 & 4,00 & 0,00 & + & + \\
\hline L.A.S.689 & 22 & 33,00 & 0,50 & 1,20 & 3,00 & 0,40 & 1,20 & 8,50 & 4,75 & 0,10 & + & + \\
\hline L.A.S.694 & 23 & 32,00 & 0,00 & 1,00 & 3,75 & 0,75 & 0,60 & 7,25 & 4,50 & 0,10 & + & + \\
\hline L.A.S.693 & 24 & 37,00 & 0,30 & 1,20 & 3,25 & 0,75 & 1,20 & 9.00 & 4,65 & 0,10 & + & + \\
\hline L.A.S.690 & 25 & 36,00 & 0,50 & 1,20 & 3,00 & 0,40 & 1,10 & 8,75 & 4,40 & 0,30 & + & + \\
\hline L.A.S.572 & 26 & 32,00 & 0,50 & 1,20 & 3,00 & 0,40 & 0,00 & 7,00 & 4,25 & 0,00 & + & + \\
\hline L.A.S.708 & 27 & 30,00 & 1,00 & 0,70 & 3,75 & 0,30 & 0,70 & 9,50 & 3,75 & 0,00 & + & + \\
\hline L.A.S. 707 & 28 & 45,50 & 1,40 & 0,90 & 3,35 & 0,60 & 0,70 & 8,28 & 5,25 & 0,20 & + & + \\
\hline L.A.S.594 & 29 & 61,50 & 1,70 & 1,70 & 3,00 & 0,50 & 0,50 & 11,50 & 6,00 & 0,00 & + & + \\
\hline L.A.S.596 & 30 & 35,00 & 0,70 & 0,70 & 2,50 & 0,50 & 0,80 & 10,00 & 5,50 & 0,00 & + & + \\
\hline L.A.S.602 & 31 & 44,00 & 0,00 & 1,00 & 3,50 & 0,00 & 0,60 & 5,50 & 3,40 & 0,00 & + & + \\
\hline L.A.S.607 & 32 & 43,00 & 1,00 & 1,00 & 3,50 & 0,50 & 0,80 & 6,50 & 3,50 & 0,30 & + & + \\
\hline L.A.S.719 & 33 & 29,50 & 1,20 & 1,00 & 3,20 & 0,40 & 1,00 & 9,50 & 4,45 & 0,50 & + & + \\
\hline L.A.S. 712 & 34 & 35,00 & 1,00 & 1,10 & 5,25 & 0,30 & 1,20 & 10,00 & 5,85 & 0,00 & + & + \\
\hline L.A.S.702 & 35 & 40,00 & 0,80 & 1,00 & 4,25 & 0,40 & 0,80 & 8,00 & 4,60 & 0,00 & + & + \\
\hline L.A.S. 700 & 36 & 45,00 & 0,70 & 1,20 & 3,50 & 1,00 & 0,70 & 7,50 & 4,75 & 0,40 & + & + \\
\hline
\end{tabular}


Tabela 2. Comparação dos caracteres morfológicos apresentados pelos exemplares de Psychotria ipecacuanha que ocorrem na Mata Atlântica, incluindo os estados de Pernambuco, Bahia, Espírito Santo, Minas Gerais, Rio de Janeiro e São Paulo. № : número correspondente na figura 64; C.P.A.: comprimento da parte aérea da planta; Diâm/raiz: diâmetro da raiz; Diâm/ramo: diâmetro do ramo; Compr. int.: comprimento do internó; Compr. peci.: comprimento do pecíolo; Compr. estip.: comprimento da estípula; Compr. folha: comprimento da folha; Larg. folha: largura da folha; Compr. acum.: comprimento do acúmen; Ramo pube.: pubescência do ramo; Pedu. pube: pubescência do pedúnculo. + (presente),- (ausente).

\begin{tabular}{lcccccccccccc}
\hline Coleção & N. & $\begin{array}{c}\text { C.P.A. } \\
(\mathrm{cm})\end{array}$ & $\begin{array}{c}\text { Diâm/ } \\
\text { raiz } \\
(\mathrm{cm})\end{array}$ & $\begin{array}{c}\text { Diâm/ } \\
\text { ramo } \\
(\mathrm{cm})\end{array}$ & $\begin{array}{c}\text { Compr. } \\
\text { int. } \\
(\mathrm{cm})\end{array}$ & $\begin{array}{c}\text { Compr. } \\
\text { peci. } \\
(\mathrm{cm})\end{array}$ & $\begin{array}{c}\text { Compr. } \\
\text { estip. } \\
(\mathrm{cm})\end{array}$ & $\begin{array}{c}\text { Compr. } \\
\text { folha } \\
(\mathrm{cm})\end{array}$ & $\begin{array}{c}\text { Larg. } \\
\text { folha } \\
(\mathrm{cm})\end{array}$ & $\begin{array}{c}\text { Compr. } \\
\text { acum. } \\
(\mathrm{cm})\end{array}$ & $\begin{array}{c}\text { Ramo } \\
\text { pube. }\end{array}$ & $\begin{array}{c}\text { Pedu. } \\
\text { pube. }\end{array}$ \\
\hline Pick.877 & 37 & 33,00 & 0,00 & 1,00 & 1,15 & 0,25 & 0,40 & 8,25 & 5,05 & 0,00 & + & + \\
SP4314 & 38 & 25,00 & 1,50 & 1,00 & 1,60 & 0,00 & 0,00 & 0,00 & 0,00 & 0,00 & + & + \\
L.A.S.767 & 39 & 35,00 & 0,00 & 1,00 & 2,00 & 0,25 & 0,70 & 9,75 & 4,75 & 0,00 & + & + \\
Kuhl.225 & 40 & 0,00 & 0,50 & 0,70 & 1,10 & 0,30 & 0,50 & 7,50 & 3,50 & 0,00 & + & + \\
L.A.S.761 & 41 & 30,00 & 0,70 & 1,00 & 1,00 & 0,00 & 0,50 & 9,25 & 3,25 & 0,00 & + & + \\
L.A.S.762 & 42 & 0,00 & 0,00 & 0,00 & 0,00 & 0,00 & 0,50 & 7,75 & 4,25 & 0,00 & + & + \\
Hoeh.52488 & 43 & 44,00 & 0,00 & 0,90 & 2,35 & 0,45 & 0,30 & 10,50 & 4,00 & 0,00 & + & + \\
L.A.S.759 & 44 & 30,00 & 0,50 & 1,20 & 1,85 & 0,00 & 0,60 & 9,00 & 4,60 & 0,10 & + & + \\
M.Barr.2002 & 45 & 59,00 & 1,50 & 1,00 & 2,75 & 0,85 & 0,50 & 6,00 & 2,85 & 0,20 & + & + \\
RFA s.n. & 46 & 50,00 & 0,00 & 1,50 & 5,00 & 0,85 & 0,70 & 6,25 & 3,25 & 0,20 & + & + \\
RFA6787 & 47 & 30,00 & 1,00 & 0,90 & 2,75 & 0,50 & 0,40 & 7,25 & 3,20 & 0,00 & + & + \\
M.Barr.1631 & 48 & 30,00 & 0,00 & 0,80 & 1,25 & 0,35 & 0,40 & 6,00 & 3,00 & 0,00 & + & + \\
L.A.S.753 & 49 & 40,00 & 0,70 & 1,00 & 3,85 & 0,00 & 0,60 & 10,00 & 4,20 & 0,30 & + & + \\
L.A.S.907 & 50 & 0,00 & 0,00 & 0,60 & 0,60 & 0,00 & 0,40 & 5,25 & 2,70 & 0,30 & + & + \\
BHCB1574 & 51 & 11,50 & 0,00 & 0,00 & 1,75 & 0,50 & 0,40 & 8,50 & 4,85 & 0,00 & + & + \\
L.A.S.746 & 52 & 40,00 & 0,00 & 1,20 & 4,00 & 0,75 & 0,40 & 7,25 & 3,50 & 0,00 & + & + \\
Glaz.2609 & 53 & 20,00 & 0,00 & 0,70 & 1,20 & 0,30 & 0,40 & 5,00 & 2,95 & 0,10 & + & + \\
RFA9244 & 54 & 35,00 & 2,00 & 1,20 & 2,50 & 0,50 & 0,40 & 9,25 & 4,25 & 0,00 & + & + \\
Sald.8484 & 55 & 40,00 & 0,00 & 1,00 & 2,00 & 1,00 & 0,70 & 7,75 & 3,35 & 0,10 & + & + \\
Sant. s. n. & 56 & 30,00 & 0,70 & 0,60 & 2,75 & 0,45 & 0,50 & 7,35 & 4,20 & 0,30 & + \\
\hline
\end{tabular}

mente, Steyermark (1972) mencionou a dificuldade de separação dos gêneros Cephaelis Sw. e Psychotria L. e considerou que apenas o último deles deve ser mantido. Esse posicionamento é, também, aceito por especialistas (D.R. Simpson, J. Kirkbride e E. Robbrecht, dados não publicados). Por esses motivos, neste trabalho considerou-se Psychotria ipecacuanha (Brot.) Stokes como o nome válido para o táxon.

Com base no material examinado é apresentada uma descrição completa da espécie incluindo dados anatômicos e número de cromossomos.

Psychotria ipecacuanha (Brot.) Stokes Bot. Mat. Med. I. p. 365. 1812 (figuras 38-58)

Sinonímia

Callicocca ipecacuanha Brot., Trans. Linn. Soc. London 6 p.137. 1802.

Ipecacuanha officinalis Arruda ex Koster., Trav. Braz. p. 497. 1816. nomen nudum

Cephaelis ipecacuanha (Brot.) A . Rich., Bull. Fac. Med. 4 p. 4: 92. 1818.

Psychotria emetica Vell., Fl. Flum. p. 64. 1825.

Uragoga ipecacuanha Baill., Hist. Plant. 7. p. 281. 1881.
Cephaelis acuminata Karsten. nomen nudum

Subarbusto ca. 50,0 cm alt. Raízes aneladas, 0,6$1,7 \mathrm{~cm}$ diâm., amareladas a esbranquiçadas quando frescas e acinzentadas quando secas. Rizoma cilíndrico, com desenvolvimento paralelo à superfície do solo, com emissão de raízes e ramos aéreos nos nós. Ramos aéreos cilíndricos, 0,6-1,9 cm diâm., entrenós 0,2-7,0 cm compr., eretos a prostrados, pubescentes na parte apical. Folhas persistentes na parte superior do ramo, ovais, elípticas a oblongas, 3,5-18,3 x $1,1-9,4 \mathrm{~cm}$, ápice arredondado, agudo ou acuminado, acúmen $0,2-1,4 \mathrm{~cm}$, base atenuada ou cuneada, membranáceas, glabrescentes em ambas as faces, discolores, buladas ou não; pecíolo $0,1-1,5 \mathrm{~cm}$ compr., glabro, pubescente quando jovem; estípulas decurrentes ou não, raramente persistentes, 4-12 laciniadas, lacínios 0,2-1,1 cm compr., glabrescentes (figura 38). Inflorescência terminal, envolvida por brácteas $0,5-1,0 \times 0,5-1,0 \mathrm{~cm}$, largamente ovais, agudas, lobadas, com dois lobos basais laterais bem destacados, pubescentes externa e internamente, esverdeadas (figuras 39-42); bractéolas 0,3-1,0 x $0,05-0,5 \mathrm{~cm}$, lineares, linear-lanceoladas a elípticas, 
obtusas a acuminadas com dois lobos basais, lanceolados, externa e internamente pubescentes, esverdeadas, envolvendo as flores (figuras 43-46); pedúnculo ereto ou deflexo, 1,2-3,5 cm compr., pubescente. Flores sésseis, $12-150$ por inflorescência, cremes ou brancas, raramente vináceas, heterostílicas. Flores brevistilas, 0,6-1,1 cm compr. ( figura 47-48); flores longistilas. 0,9-1,2 cm compr. (49-50); hipanto pubérulo, lobos do cálice com margem inteira ou denteada nas flores brevistilas, $0,2-0,5 \mathrm{~cm}$ compr., e nas longistilas $0,1-0,3 \mathrm{~cm}$ compr., pubérulo, corola 5(-6) lobada, externamente pubescente com lobos $0,2-0,4 \mathrm{~cm}$ compr., tubo da corola ligeiramente infundibuliforme, 0,2-0,6 cm compr., externamente pubérulo, internamente pubescente na região mediana onde se inserem os estames (figuras 48 e 50);

Tabela 3. Comparação dos caracteres morfológicos apresentados pelos exemplares de Psychotria ipecacuanha que ocorrem na Nicarágua, Costa Rica, Colômbia e Panamá. No: número correspondente na figura 64; C.P.A.: comprimento da parte aérea da planta; Diâm/ raiz: diâmetro da raiz; Diâm/ramo: diâmetro do ramo; Compr. int.: comprimento do internó; Compr. peci.: comprimento do pecíolo; Compr. estip.: comprimento da estípula; Compr. folha: comprimento da folha; Larg. folha: largura da folha; Compr. acum.: comprimento do acúmen; Ramo pube.: pubescência do ramo; Pedu. pube: pubescência do pedúnculo. + (presente), $-($ ausente).

\begin{tabular}{|c|c|c|c|c|c|c|c|c|c|c|c|c|}
\hline Coleção & $\mathrm{N}^{\mathrm{o}}$ & $\begin{array}{c}\text { C.P.A. } \\
(\mathrm{cm})\end{array}$ & $\begin{array}{l}\text { Diâm/ } \\
\text { raiz } \\
(\mathrm{cm})\end{array}$ & $\begin{array}{c}\text { Diâm/ } \\
\text { ramo } \\
(\mathrm{cm})\end{array}$ & $\begin{array}{c}\text { Compr. } \\
\text { int. } \\
(\mathrm{cm})\end{array}$ & $\begin{array}{c}\text { Compr. } \\
\text { peci. } \\
(\mathrm{cm})\end{array}$ & $\begin{array}{c}\text { Compr. } \\
\text { estip. } \\
(\mathrm{cm})\end{array}$ & $\begin{array}{c}\text { Compr. } \\
\text { folha } \\
(\mathrm{cm})\end{array}$ & $\begin{array}{l}\text { Larg. } \\
\text { folha } \\
(\mathrm{cm})\end{array}$ & $\begin{array}{c}\text { Compr. } \\
\text { acum. } \\
(\mathrm{cm})\end{array}$ & $\begin{array}{l}\text { Ramo } \\
\text { pube. }\end{array}$ & $\begin{array}{l}\text { Pedu. } \\
\text { pube. }\end{array}$ \\
\hline Mor.26094 & 57 & 16,00 & 1,00 & 0,80 & 0,60 & 0,30 & 0,60 & 6,25 & 3,50 & 0,50 & - & - \\
\hline Mor.23181 & 58 & 28,00 & 0,00 & 1,00 & 3,00 & 0,75 & 1,00 & 8,75 & 5,50 & 1,00 & - & - \\
\hline Sha.4678 & 59 & 35,00 & 0,00 & 0,80 & 0,95 & 0,65 & 0,00 & 9,10 & 3,40 & 0,80 & - & - \\
\hline Araq. 3025 & 60 & 37,00 & 1,00 & 0,80 & 0,85 & 0,30 & 0,70 & 10,75 & 4,50 & 0,50 & - & - \\
\hline Lag. 80 & 61 & 24,00 & 0,00 & 0,80 & 1,25 & 0,35 & 1,00 & 8,25 & 4,35 & 0,50 & - & - \\
\hline Rodr. 2 & 62 & 38,00 & 1,00 & 1,50 & 2,00 & 0,30 & 1,00 & 6,75 & 2,50 & 1,00 & - & - \\
\hline Oroz.29 & 63 & 19,00 & 2,20 & 0,80 & 1,45 & 0,60 & 0,00 & 6,50 & 2,80 & 0,30 & - & - \\
\hline Rodr. s. n. & 64 & 39,00 & 0,80 & 1,00 & 2,30 & 0,00 & 0,00 & 0,00 & 0,00 & 0,00 & - & - \\
\hline Dawe 862 & 65 & 31,00 & 1,00 & 1,30 & 1,60 & 0,35 & 0,00 & 11,00 & 5,85 & 0,50 & - & - \\
\hline Penn.4570 & 66 & 22,00 & 1,00 & 0,70 & 0,35 & 0,30 & 0,50 & 9,25 & 4,45 & 0,40 & - & - \\
\hline Penn. s. n. & 67 & 0,00 & 1,00 & 1,50 & 1,65 & 0,45 & 1,00 & 13,25 & 7,10 & 1,00 & - & - \\
\hline Clay s. n & 68 & 0,00 & 2,00 & 1,20 & 1,65 & 0,50 & 2,00 & 17,50 & 6,00 & 0,50 & + & + \\
\hline Elia 1770 & 69 & 34,00 & 2,00 & 1,00 & 2,10 & 0,00 & 0,00 & 9,50 & 4,75 & 0,40 & - & - \\
\hline MO1758758 & 70 & 45,00 & 1,00 & 1,20 & 2,00 & 1,50 & 1,00 & 10,35 & 5,60 & 1,00 & - & - \\
\hline Sex.146B & 71 & 30,00 & 0,00 & 1,20 & 0,70 & 0,20 & 0,00 & 11,00 & 5,75 & 0,50 & - & - \\
\hline Sex.146A & 72 & 30,00 & 1,70 & 1,10 & 1,80 & 0,20 & 0,40 & 11,75 & 4,50 & 0,50 & - & - \\
\hline Duke 5237A & 73 & 30,00 & 0,00 & 1,00 & 1,15 & 0,30 & 0,40 & 10,50 & 5,50 & 0,30 & - & - \\
\hline Duke 5237B & 74 & 50,00 & 0,00 & 1,00 & 1,25 & 0,35 & 0,00 & 9,40 & 4,85 & 0,50 & - & - \\
\hline Duke 8566 & 75 & 34,00 & 0,00 & 1,20 & 1,15 & 0,35 & 0,00 & 9,75 & 5,25 & 0,70 & - & - \\
\hline MO2381649 & 76 & 20,00 & 1,50 & 1,00 & 2,50 & 0,20 & 0,40 & 7,10 & 3,85 & 0,50 & - & - \\
\hline Chin. s. n. & 77 & 39,00 & 2,00 & 1,00 & 1,65 & 0,30 & 0,60 & 9,50 & 4,35 & 1,10 & - & - \\
\hline MO2704733 & 78 & 41,00 & 1,30 & 1,20 & 1,10 & 0,30 & 0,00 & 11,00 & 5,50 & 0,70 & - & - \\
\hline MO2704731 & 79 & 48,00 & 0,00 & 1,50 & 1,10 & 0,65 & 1,00 & 8,75 & 4,85 & 0,50 & - & - \\
\hline Croat4104 & 80 & 40,00 & 0,00 & 1,50 & 1,40 & 0,30 & 0,60 & 12,45 & 6,45 & 0,00 & - & - \\
\hline Croat6609 & 81 & 35,00 & 0,00 & 1,90 & 0,85 & 0,50 & 0,00 & 9,75 & 4,80 & 0,70 & - & - \\
\hline Busey 237 & 82 & 30,00 & 0,00 & 1,20 & 1,75 & 0,35 & 0,00 & 10,00 & 5,10 & 0,50 & - & - \\
\hline Croat15117 & 83 & 29,00 & 0,00 & 1,20 & 1,25 & 0,65 & 0,70 & 9,00 & 3,75 & 1,00 & - & - \\
\hline Croat4269 & 84 & 23,00 & 0,00 & 0,80 & 1,10 & 0,40 & 0,00 & 8,00 & 3,50 & 0,30 & - & - \\
\hline Croat4096 & 85 & 56,00 & 0,00 & 1,50 & 2,50 & 0,65 & 1,00 & 12,25 & 5,25 & 0,70 & - & - \\
\hline Croat 4975 & 86 & 45,00 & 1,50 & 1,20 & 1,25 & 0,20 & 0,00 & 9,75 & 4,25 & 0,50 & - & - \\
\hline Bailey 23 & 87 & 29,00 & 1,80 & 1,20 & 1,85 & 0,55 & 1,00 & 12,75 & 5,35 & 0,70 & - & - \\
\hline Scham. 767 & 88 & 28,00 & 0,00 & 1,50 & 1,25 & 0,50 & 0,70 & 9,50 & 4,50 & 0,50 & - & - \\
\hline MO1827824 & 89 & 20,00 & 0,00 & 0,70 & 0,80 & 0,40 & 0,50 & 10,00 & 4,60 & 0,20 & - & - \\
\hline Hayde 155 & 90 & 27,00 & 0,00 & 1,00 & 0,60 & 0,30 & 1,00 & 11,00 & 4,70 & 0,50 & - & - \\
\hline Hayde 127 & 91 & 23,00 & 0,00 & 1,20 & 0,75 & 0,50 & 0,00 & 10,50 & 4,70 & 0,50 & - & - \\
\hline Star 55 & 92 & 30,00 & 0,00 & 0,80 & 1,35 & 0,30 & 0,60 & 7,00 & 3,25 & 0,40 & - & - \\
\hline F642386 & 93 & 41,00 & 2,00 & 2,00 & 1,35 & 0,60 & 0,00 & 14,20 & 7,25 & 1,00 & - & - \\
\hline Croat12427 & 94 & 34,00 & 2,20 & 1,10 & 1,75 & 0,50 & 0,00 & 9,50 & 5,75 & 0,30 & - & - \\
\hline MO2704735 & 95 & 25,00 & 1,20 & 1,00 & 1,65 & 0,20 & 0,00 & 6,50 & 3,50 & 0,50 & - & - \\
\hline MO2704732 & 96 & 16,00 & 1,00 & 1,00 & 1,27 & 0,10 & 0,60 & 6,50 & 3,50 & 0,40 & - & - \\
\hline MO2704734 & 97 & 28,00 & 0,80 & 1,00 & 1,10 & 0,10 & 0,00 & 5,50 & 2,55 & 0,30 & - & - \\
\hline
\end{tabular}




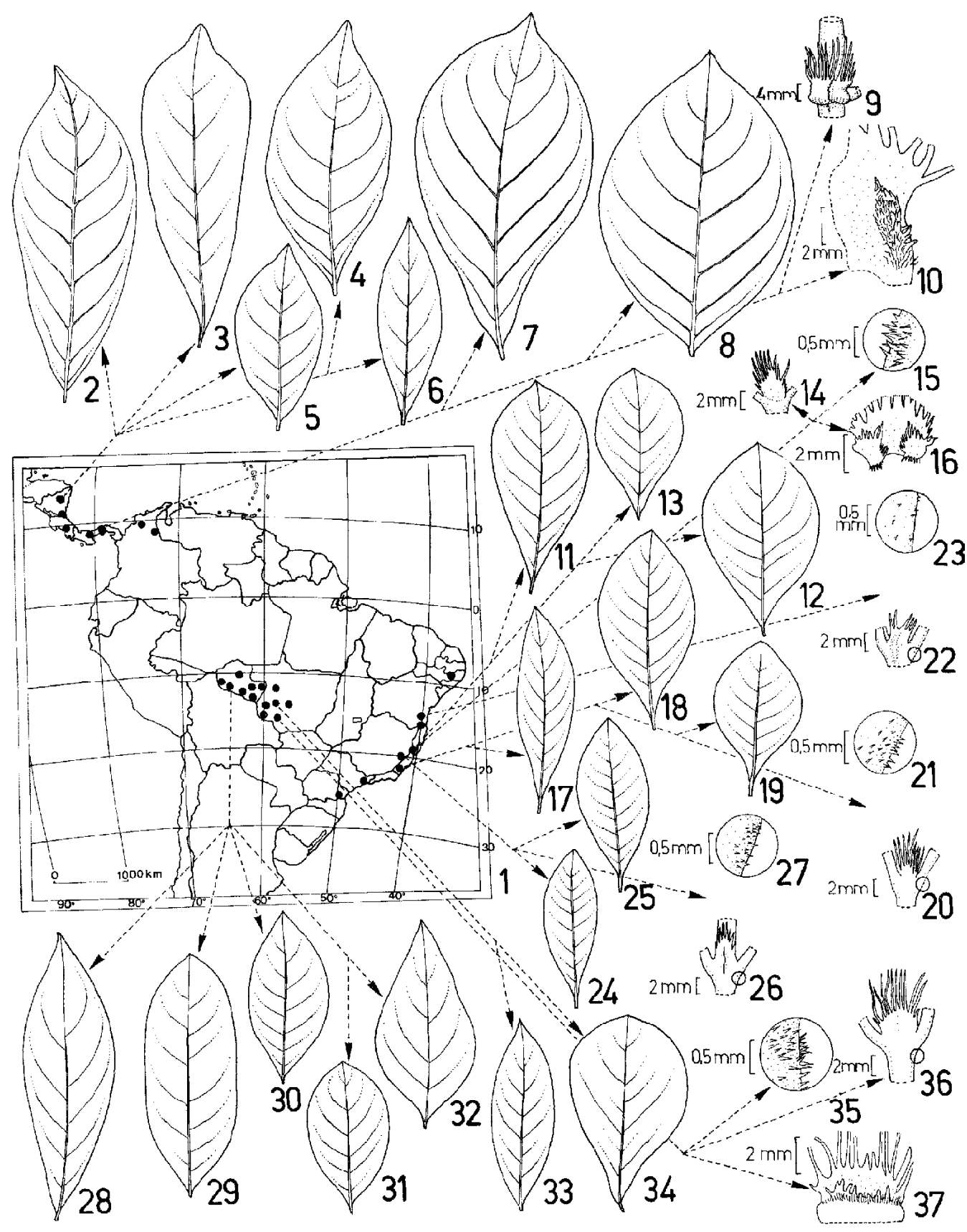

Figuras 1-37. Psychotria ipecacuanha. 1. Distribuição geográfica da espécie, baseada nos espécimens examinados. 2-6. Variação morfológica encontrada nas folhas dos espécimens examinados da Nicarágua; 2. Clay s.n. (F 1531935); 3. F 1532223; 4. Grijalva 2344; 5. Lagena 80; 6. Araquinstain 3025. 7-8. Variação morfológica encontrada nas folhas dos espécimens examinados da Costa Rica; 7. F 642386; 8. Croat 4104. 9-10. Forma da estípula e pilosidade do pedúnculo, baseada no material F 1532223 da Nicarágua. 11-16. Baseado em Skorupa 759 \& Assis do Espírito Santo; 11-13. Variação morfológica encontrada nas folhas; 14-16. Estípulas e pilosidade do pedúnculo. 17-19. Variação morfológica encontrada nas folhas, baseado em Skorupa 745 \& Assis do Rio de Janeiro. 20-23. Estípulas e pilosidade de pedúnculo; 20-21. Baseado em Skorupa 746 \& Assis do Rio de Janeiro; 22-23. Baseado em Skorupa 767 \& Assis da Bahia. 24-27. Baseado em Skorupa 753 \& Assis de Minas Gerais; 24-25. Variação morfológica da folha; 26-27. Estípulas e pilosidade do pedúnculo. 28-32. Variação morfológica encontrada nas folhas de Rondônia, baseado em Skorupa 612 \& Assis. 33-34. Variação foliar de plantas de Mato Grosso, baseadas em Skorupa et al. 712. 35-36. Estípulas e pilosidade do pedúnculo baseadas em Skorupa et al. 607 de Mato Grosso. 37. Parte interna das estípulas mostrando coléteres, baseadas em Skorupa et al. 580 de Mato Grosso. 
estames 5(-6), subsésseis nas flores longistilas (figura 51) e com filetes $0,2-0,3 \mathrm{~cm}$ compr. nas brevistilas (figura 52) glabrescentes até a base onde se tornam pubescentes, anteras dorsifixas, inclusas nas flores longistilas (figuras 49 e 51) e exsertas nas brevistilas, bitecas, deiscência longitudinal, $0,1-0,2$ $\mathrm{cm}$ compr. (figuras 47 e 52); disco do ovário urceolado, glabro (figuras 48 e 50); estilete ca. 0,2 $\mathrm{cm}$ compr. nas flores brevistilas (figura 53 ) e $0,6 \mathrm{~cm}$ nas longistilas (figura 54), glabro, estigma 2, papilosos a lanosos 0,1-0,2 cm compr. (figuras 5354). Ovário bicarpelar, bilocular com 1 óvulo em cada lóculo, placentação basal (figura 55). Fruto baga, elíptico $1,0 \times 0,7 \mathrm{~cm}$, epicarpo vermelho a vináceo, glabrescente (figura 56). Sementes 2 , retorcidas, testa dura (figuras 57-58). A análise das flores das coleções examinadas mostrou que não existem variações significativas entre os espécimes do Brasil e do exterior.

Número cromossômico: $\mathrm{n}=11$. Verdcourt (1958) e Kiehn (1986) comentam que o número básico de cromossomos para Psychotria L. é $\mathrm{x}=11$. Além disso, Kiehn (1986) reporta para Psychotria bisulcata, espécie originária da Índia, $\mathrm{n}=11$. Esses números são concordantes com o número cromossômico encontrado para Psychotria ipecacuanha (Brot.) Stokes no Brasil.

Descrição anatômica - Os coléteres foram observados na porção interna basal das estípulas e apresentam eixo multisseriado, constituído por células alongadas e envolvidas por uma epiderme em paliçada com células bem unidas (figura 59), podendo ser incluído no tipo "Standard" de Lersten (1974). Este autor considera esse tipo como o mais comum no gênero Psychotria

As raízes apresentam córtex bem desenvolvido com cerca de 25 fileiras de células e xilema composto por fileiras radiais de vasos com diâmetro semelhante ao das fibras, sendo difícil em corte transversal distinguí-lo das fibras (figura 60). Tais dados estão de acordo com os apresentados por Lemesle (1947), Metcalfe \& Chalk (1950) e Costa (1982).

Os caules jovens em corte transversal apresentam córtex bem desenvolvido, com cerca de 20 fileiras de células, com endoderme evidente e estrias de Caspary. Na estrutura secundária o xilema apresenta os elementos de vaso com diâmetro praticamente igual ao das fibras e são evidentes camadas de crescimento (figuras 61-62). A ocorrência de elementos de vasos estreitos e pequenos em Rubiaceae é muito comum (Solereder 1908, Metcalfe \& Chalk 1950, Robbrecht 1988). A ocorrência de endoderme com estrias de Caspary nas raízes é bem conhecida, mas são poucos os trabalhos que se referem à presença delas em outros órgãos aéreos das plantas (Lersten 1997). Em angiospermas Metcalfe \& Chalk (1950) listaram 25 famílias de dicotiledôneas nas quais ocorrem endoderme no caule. Quanto à presença destas estruturas no caule de Rubiaceae, até o momento não existiam citações.

As folhas são dorsiventrais, com cutícula delgada, epiderme unisseriada, hipostomática, estômatos paracíticos e tricomas uni-tricelulares, em ambas as faces. Nervura média circular, circundada por colênquima (figura 63). Venação camptódromo-broquidódroma. Tais dados estão de acordo com os de Alencar \& Santos (1980) para a espécie.

Os grãos de pólen apresentam alta viabilidade, variando entre $81-90 \%$ tanto para as plantas brevistilas como para as longistilas.

Foi feita a análise dos componentes principais, utilizando-se os 97 espécimes, buscando-se identificar a ocorrência de variação significativa ao longo da distribuição geográfica da ipecacuanha. A partir dos dados das tabelas 1, 2 e 3 foram selecionados os dois componentes principais que representavam, no conjunto, $85,5 \%$ da variabilidade total dos caracteres (figura 64). O primeiro componente principal foi a simetria da folha, que incluiu o comprimento e a largura das folhas e que representou $72,4 \%$ do total. Tal componente está representado na figura 64 , no eixo das abcissas. O segundo componente principal foi a distância entre os entrenós e que representou $13,1 \%$ da variabilidade total. Este está representado na figura 64 no eixo das ordenadas. Verificou-se que não existem grupos delimitados, mas uma sobreposição de indivíduos, o que é uma resposta da variação individual dos diferentes caracteres analisados. Nesta amostragem, destacaram-se apenas quatro indivíduos: os indivíduos 65 (Colômbia) e 39 (Brasil - Mata Atlântica) à esquerda do gráfico, que apresentaram a distância entre os entrenós $=0$. Tal caráter não estava presente nas exsicatas examinadas e foi dado o valor $=0$. $\mathrm{O}$ indivíduo 69 (Panamá), à direita no gráfico, apresentou-se destacado na amostragem por possuir as folhas muito grandes com $18 \mathrm{~cm}$ de comprimento. O indivíduo 35 (Brasil - Mato Grosso), acima no gráfico, apresentou entrenós com $6 \mathrm{~cm}$ de comprimento. 


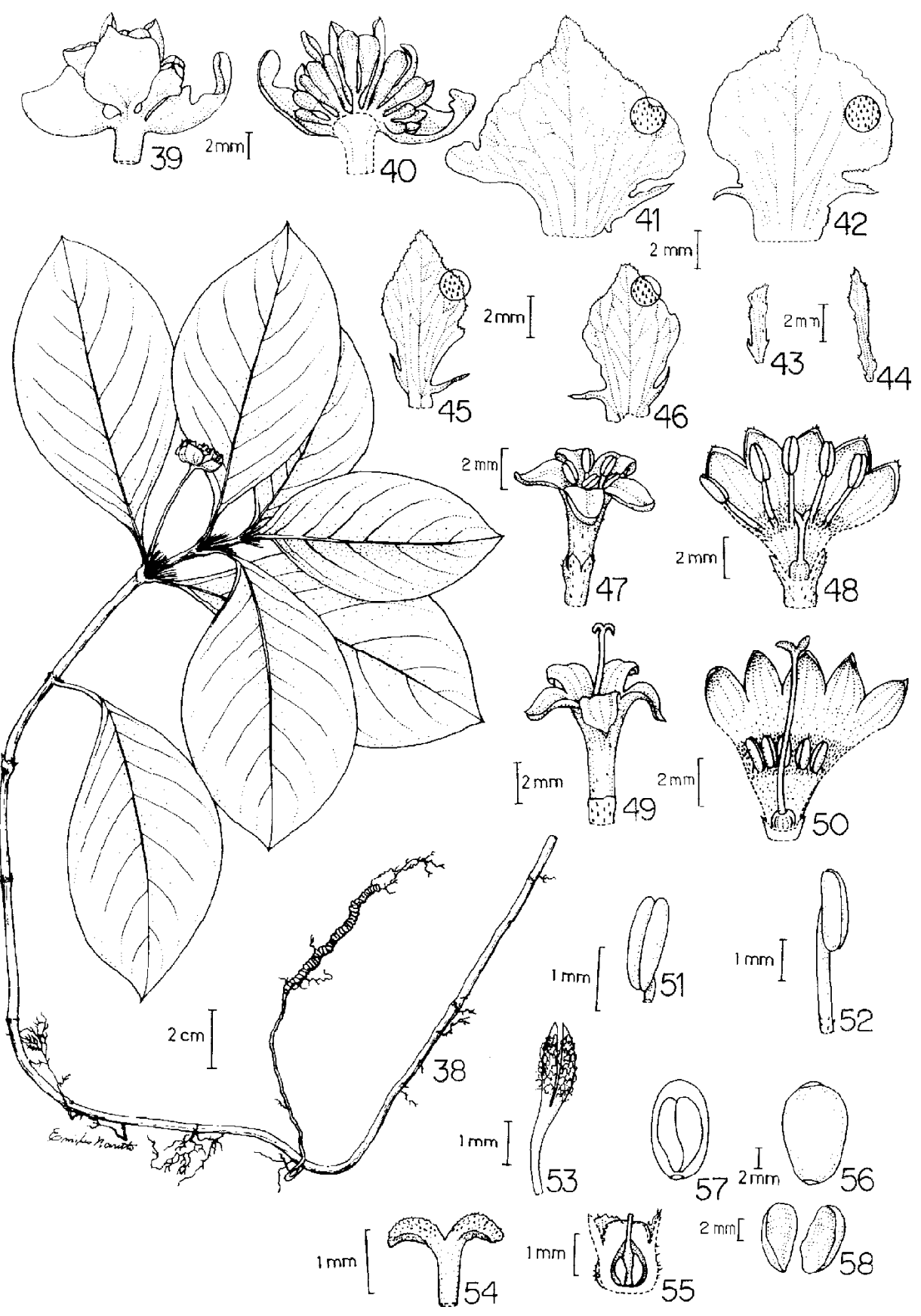

Figuras 38-58. Psychotria ipecacuanha. 38. Ramo mostrando entrenós, folhas e inflorescências e rizoma com raízes; 39. Inflorescência mostrando as brácteas; 40. Corte longitudinal da inflorescência mostrando as flores; 41-42. Variação das brácteas da inflorescência, mostrando a pilosidade em detalhe; 43-46. Variação das bractéolas de lineares (figura 43) a linear-lanceoladas (figura 44) a elípticas (figuras 45-46); 47-50. Flores brevistilas e longistilas baseadas em materiais do Brasil; 47. Flor brevistila; 48. Corte longitudinal da flor brevistila; 49. Flor longistila; 50. Corte longitudinal da flor longistila; 51. Estame da flor longistila; 52. Estame da flor brevistila; 53. Estilete e estigma da flor brevistila; 54. Estilete e estigma da flor longistila; 55. Corte longitudinal do ovário. 56. Fruto. 57. Corte longitudinal do fruto, mostrando as sementes. 58. Sementes. Figuras 47-48, 52, baseadas em Skorupa 828 \& Assis de Rondônia. Figuras 49-50, baseadas em Skorupa et al. 580 do Mato Grosso. Figuras 51, 54, baseadas em Skorupa 753 \& Assis de Minas Gerais. Figura 53 baseada em Schmalzel 767 da Costa Rica. 

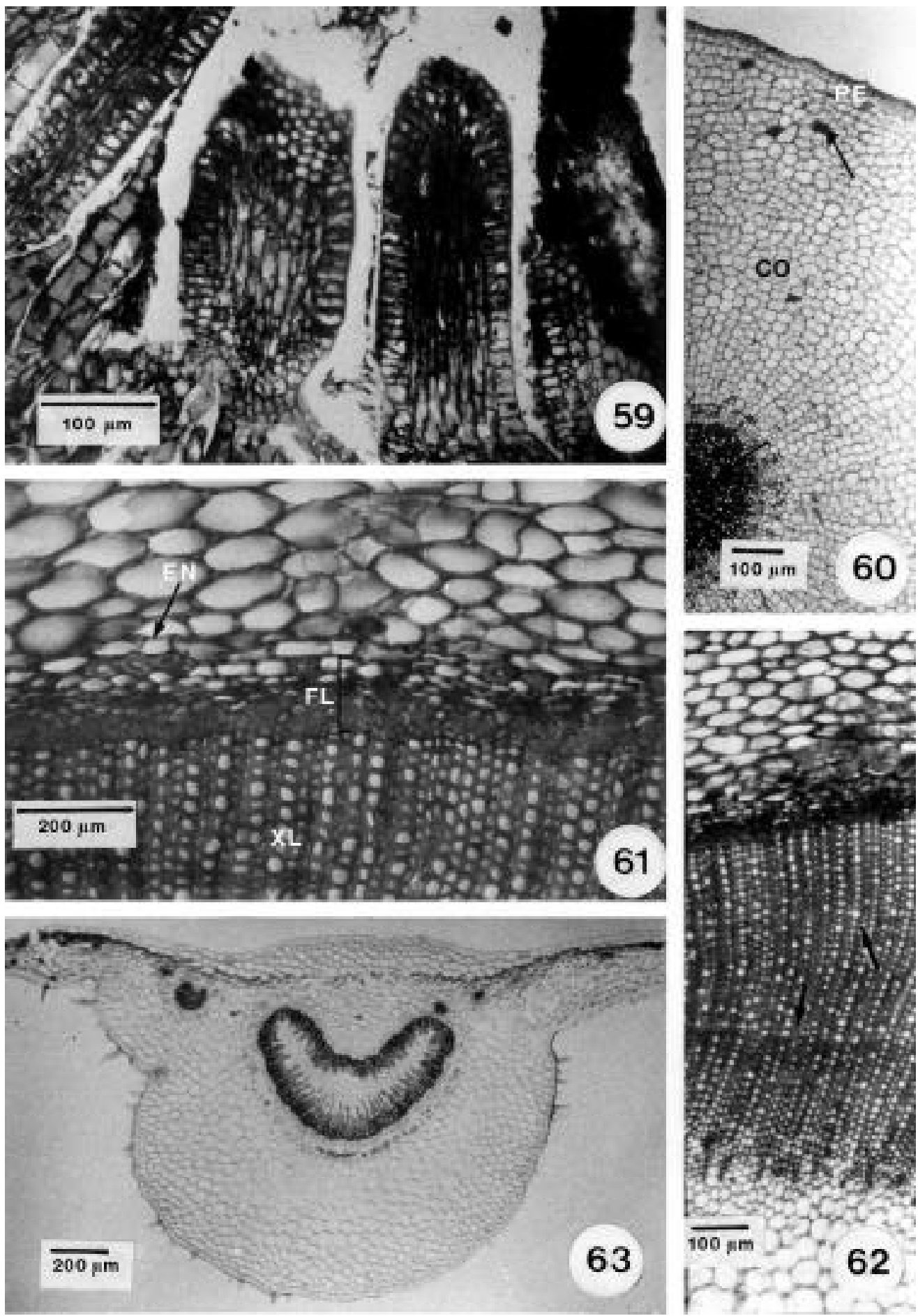

Figuras 59-63: Psychotria ipecacuanha: 59. Corte longitudinal dos coletéres mostrando o tipo "standard", com o eixo formado por células alongadas. 60. Corte transversal da raiz, a seta indica ráfides; 61 . Corte transversal do caule jovem ( $\mathrm{EN}=$ endoderme mostrando as estrias de Caspary; $\mathrm{FL}=$ floema; $\mathrm{XL}=$ xilema); 62. Corte transversal do caule adulto (as setas indicam o xilema); 63. Corte transversal da folha mostrando epiderme unisseriada e nervura central com feixe vascular circular. 
As análises apresentadas mostraram que embora ocorram diferenças individuais consideráveis entre as plantas de ipecacuanha nas várias características examinadas, estas não se refletem em agrupamentos simpátricos ou alopátricos. Assim, considera-se a ipecacuanha como uma só espécie.

Apesar das plantas que ocorrem fora do Brasil apresentarem geralmente ramos e pedúnculos glabros e acúmen das folhas maiores, ao contrário das plantas brasileiras que sempre apresentam ramos e pedúnculos pubescentes e acúmen geralmente menores, considerou-se que tais diferenças ainda não são signi- ficativas para o reconhecimento de um novo táxon infra-específico. O nome Cephaelis acuminata Karsten, verificado em exsicatas de plantas não brasileiras, também referido por Gattoni (1960) como “ipecacuanha de Cartagena”, não foi considerado neste trabalho por se tratar de um nomen nudum.

Apesar do posicionamento taxonômico apresentado neste trabalho, deve ser considerado que Psychotria ipecacuanha é representada ao longo de sua distribuição geográfica por várias populações que se distribuem disjuntamente ao longo da Mata Atlântica, de Pernambuco até o Paraná, no sul na floresta Ama-

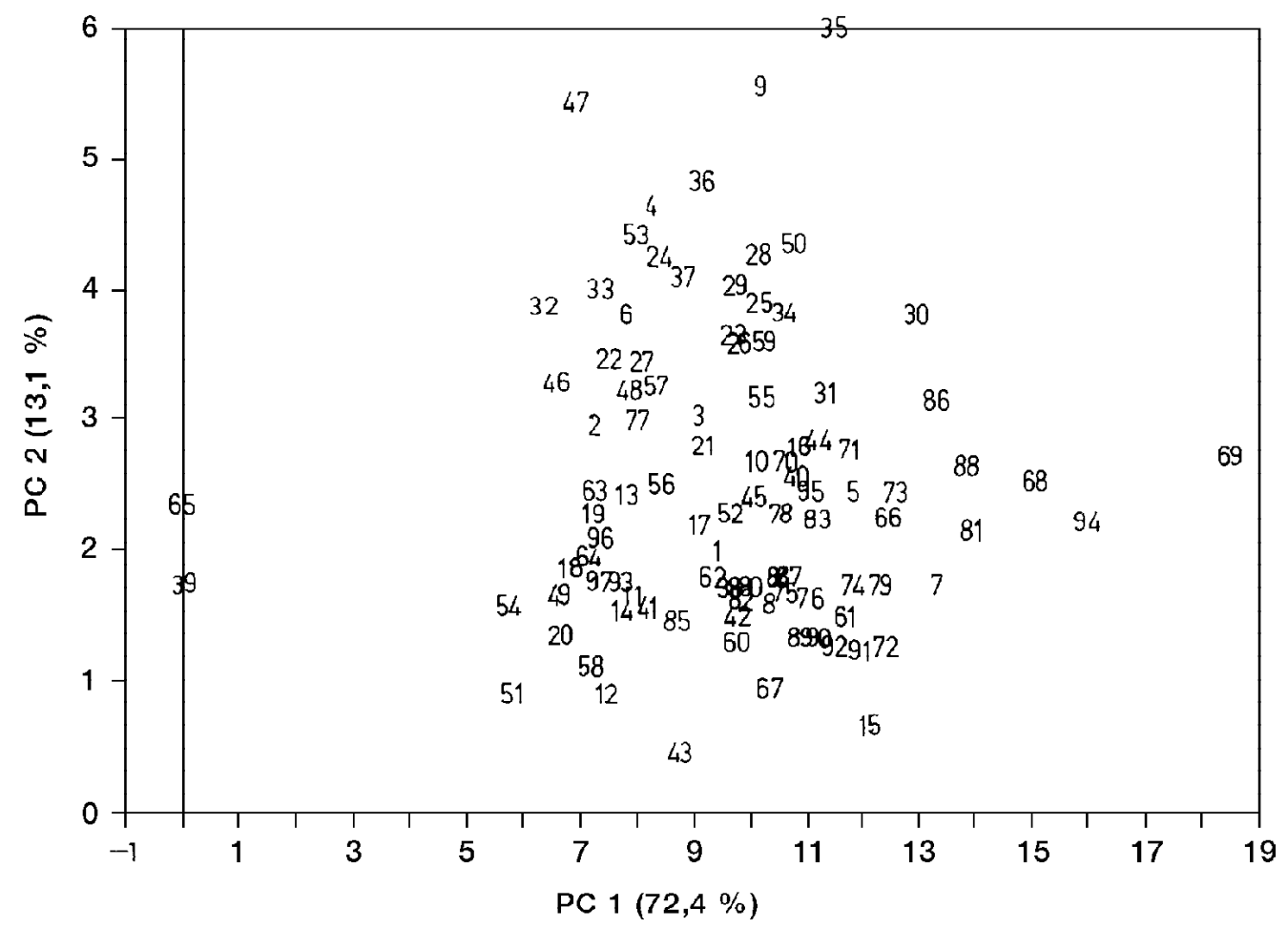

Figura 64: Análise dos componentes principais baseada em caracteres morfológicos quantitativos das populações de Psychotria ipecacuanha $. \mathrm{PC}_{1}=$ simetria da folha (larg. $\mathrm{x}$ compr.), $\mathrm{PC}_{2}=$ comprimento dos entrenós. $1=$ L.A.S. $612 ; 2=$ L.A.S. $610 ; 3=$ L.A.S $840 ; 4=$ L.A.S. $837 ; 5=$ L.A.S. $777 ; 6=$ L.A.S. $815 ; 7=$ L.A.S. $819 ; 8=$ L.A.S. $816 ; 9=$ L.A.S. $812 ; 10=$ L.A.S. $775 ; 11=$ Hoeh. $2485-$ R; $12=$ Hoeh. 2422-R; $13=$ Hoeh. 2485; $14=$ Hoeh. 927; $15=$ Hoeh. 894; $16=$ Hoeh. 2358-K; 17 = Lind. 3081; $18=$ Hoeh. 5627; 19 $=$ Hoeh. $5628 ; 20=$ SP $52716 ; 21=$ L.A.S. $580 ; 22=$ L.A.S. $689 ; 23=$ L.A.S. $694 ; 24=$ L.A.S. $693 ; 25=$ L.A.S. $690 ; 26=$ L.A.S. $572 ;$ $27=$ L.A.S. $708 ; 28=$ L.A.S. $707 ; 29=$ L.A.S. $594 ; 30=$ L.A.S. $596 ; 31=$ L.A.S. $602 ; 32=$ L.A.S. $607 ; 33=$ L.A.S. $719 ; 34=$ L.A.S $712 ; 35=$ L.A.S. $702 ; 36=$ L.A.S. $700 ; 37=$ Pick. $877 ; 38=$ SP $4314 ; 39=$ L.A.S. $767 ; 40=$ Kuhl. $225 ; 41=$ L.A.S. $761 ; 42=$ L.A.S. 762; $43=$ Hoeh. $52488 ; 44=$ L.A.S. 759; $45=$ M.Barr. 2002; $46=$ RFA s. n.; $47=$ RFA $6787 ; 48=$ M.Barr. 1631; $49=$ L.A.S. $753 ; 50$ $=$ L.A.S. $907 ; 51=$ BHCB 1574; $52=$ L.A.S. 746; $53=$ Glaz. 2609; $54=$ RFA $9244 ; 55=$ Sald. 8484; $56=$ Sant. s. n.; $57=$ Mor. 26094; $58=$ Mor. $23181 ; 59=$ Sha. $4678 ; 60=$ Araq. $3025 ; 61=$ Lag. $80 ; 62=$ Rodr. $2 ; 63=$ Oroz. $29 ; 64=$ Rodr. s. n.; $65=$ Dawe $862 ; 66=$ Penn. 4570; $67=$ Penn. s. n.; $68=$ Clay s. n.; $69=$ Elia 1770; $70=$ MO 1758758; $71=$ Sex. 146B; $72=$ Sex.. 146A; $73=$ Duke 5237A $74=$ Duke 5237B; $75=$ Duke 8566; $76=$ MO 2381649; $77=$ Chin. s. n.; $78=$ MO 2704733; $79=$ MO 2704731; $80=$ Croat $4104 ; 81$ $=$ Croat $6609 ; 82=$ Croat $237 ; 83=$ Croat $15117 ; 84=$ Croat $4269 ; 85=$ Croat $4096 ; 86=$ Croat $4975 ; 87=$ Bailey $23 ; 88=$ Scham. $767 ;$ $89=$ MO 1827824; $90=$ Hayde 155; $91=$ Hayde $127 ; 92=$ Star. 55; $93=$ F 642386; $94=$ Croat 12427; $95=$ MO 2704735; $96=$ MO 2704732; $97=$ MO 2704734; $98=$ Busey 237 
zônica, nos Estados de Rondônia e Mato Grosso, e na Colômbia e América Central (figura 1). Essas pequenas populações podem ou não estar trocando genes entre si, porém dificilmente as plantas da Mata Atlântica trocam genes com os da floresta Amazônica ou das florestas de fora do Brasil. Tal situação levará essas populações a taxas de especiação diferentes, podendo levar à formação de táxons infra-específicos não detectados com a metodologia utilizada neste trabalho.

Distribuição geográfica e conservação - Psychotria ipecacuanha com base no material examinado, apresenta distribuição disjunta nas florestas úmidas da América Central (Nicarágua, Costa Rica e Panamá) e norte da América do Sul (Colômbia), sul da Amazônia (Rondônia e Mato Grosso) e ao longo da Mata Atlântica no Nordeste (Pernambuco e Bahia) e Sudeste (Espírito Santo, Minas Gerais, Rio de Janeiro, São Paulo e Paraná). Porém, deve ser destacado que, apesar das várias expedições realizadas, tal espécie não foi mais coletada em Pernambuco, onde a última coleta é de B. Pickel em 1925, em São Paulo, onde a última coleta é de N. Santos em 1940, e no Paraná, onde a última coleta é de P. Dusén em 1911. Tal situação é muito preocupante pois verificou-se, também, que as populações localizadas estão em áreas sob grande impacto, seja na Mata Atlântica, seja no sul da Amazônia. As populações localizadas são descontínuas e, geralmente, formadas por poucos indivíduos. Acrescenta-se, também, que o extrativismo da espécie pela retirada das raízes exerce grande impacto, especialmente sobre as populações amazônicas.

Visando a conservação da espécie e a garantia de produção desse recurso natural, estas plantas estão sendo mantidas em casas de vegetação no CENARGEN, em Brasília e no campo em área de subosque no CPATU, em Belém. Recomenda-se a delimitação de áreas para cultivo no subosque de florestas úmidas da Amazônia e Mata Atlântica, ou o manejo com aumento das populações naturais através do estabelecimento de reservas extrativistas nos moldes de outras já existentes no país.
Agradecimentos - L. A. Skorupa pelo trabalho de campo, sugestões e leitura crítica, além do apoio e companheirismo durante a realização deste trabalho; à D. Zappi pelas sugestões e leitura crítica do manuscrito; ao B. M. T. Walter pelo auxílio na formatação deste trabalho; ao CNPq, CAPES e EMBRAPA/CENARGEN pelo apoio financeiro.

\section{Referências bibliográficas}

ADDOR, A.A. 1945. Considerações acerca da Poaia. Bol. Minist. Agric. 34:1-28.

AKERELE, O., HEYWOOD, V. \& SINGE, H. 1991. The conservation of medicinal plants. Cambridge University Press, Cambridge.

ALENCAR, B.M.C.M. \& SANTOS, A.V.P. 1980. Contribuição ao conhecimento da anatomia foliar da ipeca (Cephaelis ipecacuanha (Brot.) A. Rich.). Cien. \& Cult. 32:868-872.

BROTERO, F.A . 1802. Description of Callicocca ipecacuanha. Trans. Linn. Soc. 6:137-141.

COSTA, A.F. 1982. Ipecacuanha. Farmacognosia. Vol. 4. 2 ed. Fundação Calouste Gulbenkian, Lisboa.

FIGUEIREDO, A.P. 1935. Instruções para o cultivo da poaia. O Campo 6:47-48.

GATTONI, L.A. 1960. A raiz da ipecacuanha. A fazenda 55:16-18.

JOHANSEN, D.A. 1940. Plant microtechnique. Macgrow Hill Book Inc., New York.

KIEHN, M. 1986. Kariosystematic studies on Rubiaceae: chromosome counts from Sri Lanka. Pl. Syst. Evol. 154:213-223.

LEMESLE, M.R. 1947. La constitution anatomique du bois secondàire chez ipecacuanhas vrais. Revista Gen. de Bot. $54: 138-151$.

LERSTEN, N.R. 1974. Morphology and distribution of colleters and crystals in relation to the taxonomy and bacterial leaf nodule symbiosis of Psychotria (Rubiaceae). Amer. J. Bot. 61:973-981.

LERSTEN, N.R. 1997. Occurrence of endodermis whith a Casparianian strip in stem and leaf. Bot. Rev. 63:265-271.

METCALFE, C.R. \& CHALK, L. 1950. Anatomy of the dicotiledons. Vol. 1. Claredon Press, Oxford.

MORRISON, D.F. 1976. Multivariate statistical methods. McGraw Hill Book Company, New York.

ROBBRECHT,E. 1988. Tropical woody Rubiaceae. Characteristics features and progressions. Contribution to a new subfamilial classification. Nationale Plantentuim van Belgie 1: 11, Meise.

ROESER, K.R. 1962. Die Nodel der Schwarzkiefermassenproduct und Kunstwert der Natur. Mikrokosmos 61:33-36.

SASS, J. E. 1951. Botanical microtechnique. Iowa State College Press, Ames.

SOLEREDER, H. 1908. Systematic anatomy of the dicotyledons. Claredon Press, Oxford.

STAFLEU, F.A. 1981. Index Herbariorum. 7 ed. (Regnum Vegetabilis 106). Scheltemma \& Holkema, Utrecht.

STEYERMARK, J. A . 1972. The botany of the Guayana Highland part IX. Rubiaceae. Mem. New York Bot. Gard. 23:227-832.

TORRES, L.A.C. 1972. Contribuición al conocimiento de la Cephaelis ipecacuanha (Brot.) A. Rich., con especial referencia a Colombia. In Simpósio internacional sobre plantas de interesse económico de la Flora Amazónica - IICA - Tropicos, Belém.

VERDCOURT, B. 1958. Remarks on the classification of the Rubiaceae. PhD thesis. University of Reading, Reading. 